\title{
The effects of estradiol on inflammatory and endothelial dysfunction in rats with preeclampsia
}

\author{
ZHAO-HENG LIN, JING JIN and XI-YUN SHAN \\ Department of Intensive Care Unit, The People's Hospital of Xishuangbanna Dai Autonomous Prefecture, \\ Jinghong, Yunnan 666100, P.R. China
}

Received June 3, 2019; Accepted October 23, 2019

DOI: $10.3892 /$ ijmm.2020.4465

\begin{abstract}
Preeclampsia (PE), a hypertensive disorder during pregnancy, has adverse effects to both the mother and the fetus. Maternal inflammatory and vascular endothelial dysfunction are important factors in the pathogenesis of PE. The present study aimed to investigate the effects of estradiol (E2) on inflammatory and endothelial dysfunction in an $\mathrm{N}$ (omega)-nitro-L-arginine methyl ester (L-NAME)-induced rat model of PE. Adult pregnant female Sprague-Dawley rats were divided into four equal groups between days 7 and 11 of gestation and treated as follows: i) Pregnant rats receiving daily intraperitoneal (i.p.) injections of equal volume of $0.9 \%$ normal saline (NS) (Control group, $n=12$ ); ii) pregnant rats receiving daily i.p. injections of L-NAME at $50 \mathrm{mg} / \mathrm{kg}$ (L-NAME group, $\mathrm{n}=12$ ); iii) pregnant rats receiving a daily i.p. injection of $50 \mathrm{mg} / \mathrm{kg}$ L-NAME and NS from day 11 (L-NAME + NS group, $\mathrm{n}=12$ ); and iv) pregnant rats receiving daily i.p. injections of $50 \mathrm{mg} / \mathrm{kg} \mathrm{L-NAME}$ and $100 \mu \mathrm{g} / \mathrm{kg} /$ day E2 from day 11 (L-NAME + E2 group, $n=12$ ). On day 21, blood pressure (BP) and the level of 24-h urine protein in the maternal rats, fetal weight and percentage of stillbirths following a cesarean section were recorded. The activities of nitric oxide (NO) and inducible NO synthase (iNOS), the levels of inflammatory cytokines [interleukin (IL)-1 $\beta$, IL-6, interferon- $\gamma$ and monocyte chemoattractant protein-1], adherence factors (CD49d, intracellular adhesion molecule 1 and lymphocyte function-associated antigen-1) and uterine angiogenic status (Fms-like tyrosine kinase-1, vascular cell adhesion molecule and matrix metalloproteinase 2/9) were also assessed. In addition, the histopathology of the placenta, the expression of estrogen receptor $\alpha 36$ (ER $\alpha 36), E R \alpha, E R \beta$ and $\mathrm{G}$ protein-coupled ER, as well as the activation of the
\end{abstract}

Correspondence to: $\mathrm{Dr}$ Zhao-Heng Lin, Department of Intensive Care Unit, The People's Hospital of Xishuangbanna Dai Autonomous Prefecture, 4 Galan South Road, Jinghong, Yunnan 666100, P.R. China

E-mail: linzhaoheng_dz@163.com

Key words: preeclampsia, estradiol, inflammatory, endothelial dysfunction, toll-like receptor 4 toll-like receptor 4 (TLR4) signaling pathway (TLR4, myeloid differentiation primary response 88 , IL-1 receptor-associated kinase 4 and tumor necrosis factor receptor-associated factor 6) were evaluated by H\&E staining, immunofluorescence and western blot assays. Treatment with L-NAME increased the $\mathrm{BP}$, urine protein and rate of stillbirths and suppressed fetal weight compared with those in the control group. The L-NAME-induced effects were attenuated by the administration of E2. In addition, the administration of E2 decreased inflammation and NO levels and altered the uterine angiogenic status. The histological analysis of PE rat placenta in the E2-treated group confirmed the effects on biochemical parameters. Of note, E2 treatment significantly suppressed the TLR4 signaling pathway. In the rat model of PE, adverse outcomes including BP, fetal rat weight and proteinuria, high neonatal death rate, inflammatory response, oxidative stress and endothelial dysfunction were attenuated by exogenous E2 administration, which may present a novel approach for the clinical treatment of PE.

\section{Introduction}

Preeclampsia (PE) is a hypertensive condition that occurs during pregnancy. It is the major cause of maternal and perinatal death, premature birth and fetal growth restriction; the pathogenesis is complex and effective treatments are currently lacking $(1,2)$. PE is a chronic disease, which frequently leads to multiple organ failure in the body of the pregnant woman, increases the production of reactive oxygen species, causes maternal inflammation and accelerates apoptosis, leading to an imbalance between the formation of normal placentation and pro-angiogenic factors (3). Previous studies have demonstrated that compared with non-pregnant females, those with normal pregnancy and patients with PE exhibit an inflammatory response, and that patients with $\mathrm{PE}$ exhibit excessive activation of the inflammatory response compared with normal pregnant subjects, including increased levels of inflammatory cytokines and products of oxidative stress $(4,5)$. These results suggest that the inflammatory response has a crucial role in the pathogenesis of PE.

PE may lead to the dysfunction of vascular endothelial cells and increase endothelin secretion (6). Under normal conditions, the expression levels of intercellular adhesion molecule-1 (ICAM-1), vascular cell adhesion molecule-1 (VCAM-1) 
and leukocyte function-associated antigen (LFA-1) are low, allowing neutrophils to roll along the endothelium without adhesion (7). However, the content of the pro-inflammatory cytokines tumor necrosis factor- $\alpha$ (TNF- $\alpha$ ), interferon- $\gamma$ (IFN- $\gamma$ ), interleukin (IL)-1 and monocyte chemoattractant protein (MCP)-1 is increased in the blood of patients with PE, which activates the molecular adhesion ligands on the vascular endothelium and leukocytes, thus significantly upregulating the levels of ICAM-1 and LFA-1, which interact with each other. Endothelial cells firmly bind to neutrophils to induce endothelial damage $(7,8)$. In addition, vascular endothelial growth factor, placental growth factor and soluble Fms-like tyrosine kinase-1 (sFLT-1) lead to the general activation of the maternal inflammatory system, dysfunction of widespread endothelial cells and limitation of placental vascularization $(9,10)$. Several studies have indicated that the secretion levels of multiple IL-1 family members in the maternal circulatory system and placental chorionic trophoblast cells are significantly increased $(11,12)$, which serves an important role in promoting the development of PE.

Previous studies have described the effects of two steroid hormones, estrogen and progesterone, on vascular endothelial and smooth muscle cells (13). As a vascular endothelial protective factor maintains vascular tension and blood pressure stability, the decrease in estradiol (E2) levels may be induce cardiovascular disease (14). It has been indicated that the levels of E2, propylene glycol and progesterone are abnormal in PE (15), but the details of these changes and specific effects remain elusive.

Although it has been reported that the expression of E2 is low in patients with $\mathrm{PE}$, the exact mechanism remains unclear (16). The aim of the present study was to investigate whether treatment with exogenous E2 may improve inflammatory and endothelial dysfunction in a rat model of PE.

\section{Materials and methods}

Animals. A total of 48 adult Sprague-Dawley rats weighing 210-250 g (age, 7 weeks) were purchased from the Department of Experimental Zoology of Kunming Medical University (Kunming, China). All rats had ad libitum access to food and water and were maintained in a stable environment at $21 \pm 3^{\circ} \mathrm{C}$, $62 \pm 3 \%$ humidity and a 12 -h light/dark cycle. The female rats were caged for $24 \mathrm{~h}$ with a male rat, and mating was confirmed by the presence of a vaginal plug and spermatozoa in the vaginal smear. The day on which insemination was detected was designated as day 1 of pregnancy. The protocols of the animal experiments followed the NIH Guide for the Care and Use of Laboratory Animals and the study was approved by the Experimental Animal Ethics Committee of Kunming Medical University and the Commission for Animal Experimentation of The People's Hospital of the Xishuangbanna Dai Nationality Autonomous Prefecture.

Treatment and experimental grouping. The rats were randomly divided into four groups on day 7 as follows: i) Normal pregnant rats receiving daily intraperitoneal (i.p.) injections of equal volume of $0.9 \%$ normal saline (NS) (Control group, $n=12$ ); ii) pregnant rats receiving daily i.p. injections of $50 \mathrm{mg} / \mathrm{kg}$ L-NAME (L-NAME group, $\mathrm{n}=12$ ); iii) pregnant rats receiving daily i.p. injections of $50 \mathrm{mg} / \mathrm{kg}$ L-NAME and NS from day 11 (L-NAME + NS group, $\mathrm{n}=12$ ); iv) pregnant rats receiving daily i.p. injections of $50 \mathrm{mg} / \mathrm{kg}$ L-NAME plus $100 \mu \mathrm{g} / \mathrm{kg} /$ day E2 from day 11 (L-NAME + E2 group, $\mathrm{n}=12$ ).

On days 13 and 21 of gestation, 24-h urine of rats was collected using metabolic cages (Yuyan Instruments) for the determination of urinary protein. The level of urine protein was measured using a Rat Urinary Protein kit (Sigma-Aldrich; Merck KGaA).

Blood pressure (BP) measurement. On days 13 and 21, rat BP was measured using the non-invasive tail cuff method after rats had been pre-warmed in a heating chamber at $37^{\circ} \mathrm{C}$ for $15 \mathrm{~min}$. The BP measurement was repeated five times, and the mean value for each rat was obtained.

Determination of fetal weight and rate of stillbirths. On day 21 of pregnancy, rats were anesthetized with $2 \%$ sodium pentobarbital at the dose of $50 \mathrm{mg} / \mathrm{kg}$ and placed in the supine position for delivery by cesarean section. The following parameters were determined: Litter size, number of stillbirths and surviving neonates. Subsequently, fetal weight was determined by dividing the total weight of all pups and placentas in each litter by the number of pups in that litter. Under terminal anesthesia, blood samples were collected from the maternal rat by intracardiac puncture for ELISA and placenta tissue was harvested for histopathologic analysis; placental homogenate was prepared for mRNA and protein detection. At the end of the experiment, the surviving pups were euthanized with $2 \%$ sodium pentobarbital.

$H \& E$ staining. For the histopathologic analysis of the placenta, tissue samples were fixed in $10 \%$ phosphate-buffered formalin for $48 \mathrm{~h}$ at room temperature, embedded in paraffin, cut into 5 -mm sections and placed on slides. Subsequently, the sections were stained with $0.5 \% \mathrm{H} \& \mathrm{E}$ solution and examined under a light microscope (Olympus Corporation) under x200 magnification. Five visual fields of the placenta tissue on each section were selected randomly.

Cytokine determination using ELISA. Cytokine levels of IL-1 $\beta$, IL-6, IFN- $\gamma$, MCP-1 and sFlt-1 in the serum of each maternal rat and the activity levels of nitric oxide (NO) and inducible NO synthase (iNOS) in the homogenate of placenta tissue were determined by ELISA with rat ELISA kits IL-1 $\beta$ (ml003057), IL-6 (ml102828), IFN- $\gamma$ (ml064291), MCP-1 (ml002960), sFlt-1 (ml059017), NO (ml059000) and iNOS (ml003127) purchased from Shanghai Enzyme-linked Biotechnology Co., Ltd. according to the manufacturer's protocols. The absorbance in each group was detected using a microplate reader at $450 \mathrm{~nm}$.

Western blot analysis. Total proteins were extracted from the placenta tissue homogenates using RIPA lysis buffer (Sigma-Aldrich; Merck KGaA), and a bicinchoninic acid protein assay kit (Pierce; Thermo Fisher Scientific, Inc.) was used to determine the protein concentration. Proteins ( $45 \mu \mathrm{g} /$ lane) were separated by $8-10 \%$ SDS-PAGE and transferred onto polyvinylidene fluoride membranes (Beyotime Institute of Biotechnology). The membranes were blocked 
in $5 \%$ skimmed milk at room temperature for $1 \mathrm{~h}$ prior to incubation with the primary antibodies against IL-1 $\beta$ (cat. no. ab2105; 1:1,000; Abcam), IL-6 (cat. no. 12153; 1:1,000; Cell Signaling Technology, Inc.), IFN- $\gamma$ (cat. no. 3159; 1:1,000; Cell Signaling Technology, Inc.), MCP-1 (cat. no. ab25124; 1:2,000; Abcam), CD49D (cat. no. ab75760; 1:1,000; Abcam), ICAM1 (cat. no. ab171123; 1:1,000; Abcam), LFA-1 (cat. no. ab52895; 1:2,000; Abcam), sFlt-1 (cat. no. ab9540; 1:1,000; Abcam), VCAM1 (cat. no. ab174279; 1:1,000; Abcam), MMP2 (cat. no. ab92536; 1:2,000; Abcam), MMP9 (cat. no. ab137867; 1:1,000; Abcam), ER $\alpha$ (cat. no. ab16460; 1:1,000; Abcam), ER $\beta$ (cat. no. ab3576; 1:1,000; Abcam), GPER (cat. no. ab39742; 1:1,000; Abcam), TLR4 (cat. no. ab217274; 1:500; Abcam), myeloid differentiation primary response 88 (MyD88; cat. no. ab2064; 1:500; Abcam), phospho (p)-IL-1 receptor-associated kinase 4 (IRAK4; cat. no; 11927, 1:1,000; Cell Signaling Technology, Inc.), IRAK4 (cat. no. 4363; 1:1,000; Cell Signaling Technology, Inc.), TNF receptor-associated factor 6 (TRAF6; cat. no. ab33915; 1:2,000; Abcam) and ER $\alpha 36$ (cat. no. CY1109; 1:1,000; Cell Applications, Inc.) at $4^{\circ} \mathrm{C}$ overnight. Subsequently, the membranes were incubated with horseradish peroxidase-conjugated goat anti-mouse (cat. no. ab205719; 1:2,000; Abcam) or anti-rabbit (cat. no. ab205718; 1:2,000; Abcam) IgG secondary antibodies for $2 \mathrm{~h}$ at room temperature. The membranes were visualized using an enhanced chemiluminescence system (Beyotime Institute of Biotechnology) and densitometry analysis was performed using Image $\mathbf{J}$ software (version 1.47; National Institutes of Health). GAPDH (cat. no. ab181602; 1:10,000; Abcam) expression was used as an internal control.

Total RNA isolation and reverse transcription-quantitative $P C R(R T-q P C R)$. Total RNA was extracted from the placenta tissue homogenate of each rat using $\mathrm{TRIzol}^{\circledR}$ reagent (Invitrogen; Thermo Fisher Scientific, Inc.). Total RNA was reverse-transcribed into cDNA using SuperScript ${ }^{\mathrm{TM}}$ III Reverse Transcriptase (Invitrogen; Thermo Fisher Scientific, Inc.) according to the manufacturer's protocol. The reverse transcription conditions were $10 \mathrm{~min}$ at $25^{\circ} \mathrm{C}, 30 \mathrm{~min}$ at $48^{\circ} \mathrm{C}$ and 5 min a $95^{\circ} \mathrm{C}$. RT-qPCR was performed on a 7500 Fast Real-Time PCR System Light Cycler (Applied Biosystems; Thermo Fisher Scientific, Inc.) using a $20-\mu 1$ reaction system that was incubated as follows: $95^{\circ} \mathrm{C}$ for $2 \mathrm{~min}$, followed by 40 cycles of $95^{\circ} \mathrm{C}$ for $20 \mathrm{sec}$ and $72^{\circ} \mathrm{C}$ for $30 \mathrm{sec}$. The PCR was repeated three times and the primer sequences were as follows: ER $\alpha 36$ forward, 5'-CCAAGAATGTTCAACCACAACCT-3' and reverse, 5'-GCACGGTTCATTAACATCTTTCTG-3'; GADPH forward, 5'-ACAGTCAGCCGCATCTTCTT-3' and reverse, 5'-GACAAGCTTCCCGTTCTCAG-3'. The relative expression of mRNAs was determined using the $2^{-\Delta \Delta \mathrm{Cq}}$ method (17) with normalization to GAPDH expression.

Immunofluorescence (IF) staining of rat placenta tissue. IF staining was performed on placenta tissue by cutting $5 \mu \mathrm{m}$-thick paraffin sections and incubating them with an antibody against ER $\alpha 36$ (cat. no. CY1109; 1:100; Cell Applications Inc.) at $4^{\circ} \mathrm{C}$ overnight. The sections were washed and incubated at room temperature for $1 \mathrm{~h}$ with an Alexa Fluor 488-conjugated anti-rabbit IgG secondary antibody (cat. no. ab150077; 1:500; Abcam). The nuclei were stained with
DAPI (Invitrogen; Thermo Fisher Scientific, Inc.). The images were captured under a TCS SP5 confocal microscope (Leica Microsystems; magnification, x200). The intensity of green fluorescence in the images represents the protein expression of $\mathrm{ER} \alpha 36$.

Statistical analysis. Data are expressed as the mean \pm standard derivation. Statistical analyses were performed using SPSS software (version 17.0; SPSS, Inc.). The statistical significance of differences among multiple groups was determined by one-way analysis of variance followed by Dunnett's post-hoc test. The correlation between sFlt-1 expression and the level of other cytokine levels, including IL-1 $\beta$, IL-6, IFN- $\gamma$ and MCP-1, was examined using Pearson's correlation analysis. Each experiment was performed at least three times. $\mathrm{P}<0.05$ was considered to indicate statistically significant difference.

\section{Results}

Effects of E2 on blood pressure and urine protein content. No significant difference in systolic BP was observed among the four groups on day 13 (P>0.05; Fig. 1A). On day 21, BP in the L-NAME group was higher compared with that in the control group $(\mathrm{P}<0.05$; Fig. 1A), but it was decreased by E2 treatment $(\mathrm{P}<0.05$; Fig. 1A). These results suggested that E2 treatment prevented the elevation of BP in rats with PE (18).

Similarly, no significant difference in 24-h urine protein was observed among the four groups on day 13 ( $\mathrm{P}>0.05$; Fig. 1B). However, on day 21, the 24-h urine protein content was significantly higher in the L-NAME group compared with that in the control group $(\mathrm{P}<0.001$; Fig. 1B), whereas the L-NAME + E2 group exhibited a significant decrease in urine protein content compared with that in the L-NAME group $(\mathrm{P}<0.01$; Fig. 1B). These results suggested that $\mathrm{E} 2$ was effective in preventing the elevation of urine protein in rats with PE.

Effects of E2 on fetal weight and the rate of stillbirths. Compared with the control group, a significant decrease fetal weight was observed in the L-NAME group ( $\mathrm{P}<0.01$; Fig. $1 \mathrm{C})$. However, E2 treatment restored the weight of neonates in the L-NAME + E2 group to the level in the control group $(\mathrm{P}<0.01$; Fig. 1C), whereas no significant differences were identified between the L-NAME and L-NAME + NS groups. In addition, the rate of stillbirths in the L-NAME group was increased compared with that in the control group $(\mathrm{P}<0.001$; Fig. 1D), whereas the L-NAME + E2 group exhibited a decrease compared with the L-NAME group $(\mathrm{P}<0.001$; Fig. 1D); however, E2 treatment did not restore the number of stillbirths to the control level. Therefore, compared with that in the normal pregnant rats in the control group, the rate of stillbirths in the L-NAME + E2 group was still high. The results demonstrated that treatment with $\mathrm{E} 2$ partially protected the fetuses of rats with PE against the effects of L-NAME, increasing the fetal weight and reducing the rate of stillbirths.

Effects of E2 on placental histopathology. Histopathological examination with $H \& E$ staining revealed degeneration in the placenta from the rats in the L-NAME and L-NAME + NS 

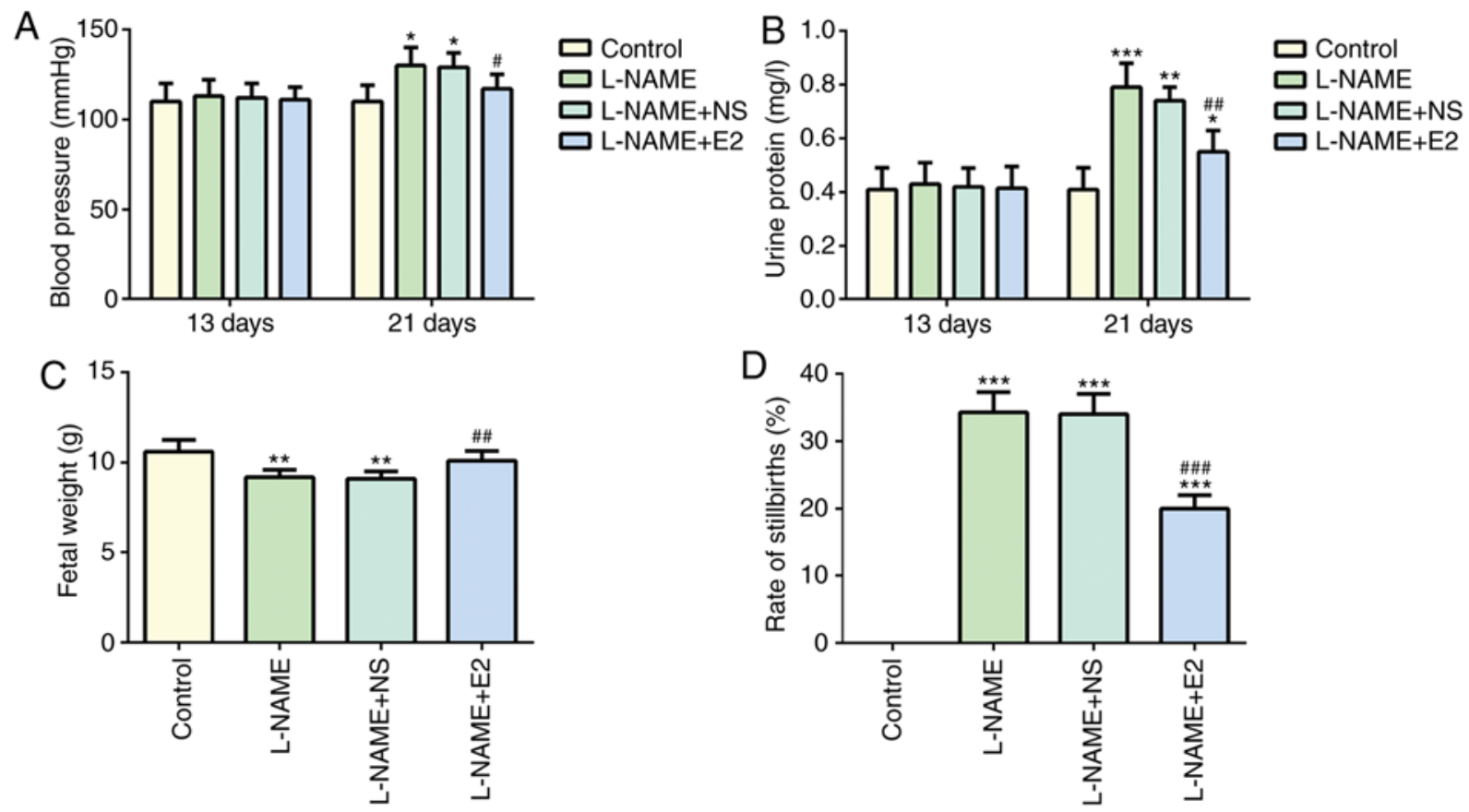

Figure 1. Effects of E2 on the adverse pregnancy outcome of rats with preeclampsia. (A) Blood pressure and (B) urine protein for $24 \mathrm{~h}$ on days 13 and 21 of gestation in rats in the four groups. (C) Fetal weight and (D) rate of stillbirths on day 21 of gestation in the four groups. $\mathrm{n}=12$ rats/group. ${ }^{*} \mathrm{P}<0.05$, ${ }^{* *} \mathrm{P}<0.01$ and ${ }^{* * * *} \mathrm{P}<0.001$ vs. control; ${ }^{\#} \mathrm{P}<0.05,{ }^{\# \#} \mathrm{P}<0.01$ and ${ }^{\# \# \#} \mathrm{P}<0.001$ vs. L-NAME and L-NAME + NS. L-NAME, N (omega)-nitro-L-arginine methyl ester; NS, normal saline; E2, estradiol.

groups, including necrotic changes and inflammatory cell infiltration (Fig. 2A). However, these were absent in the L-NAME + E2 group. Therefore, E2 treatment reduced inflammatory infiltration in placenta tissue of rats with PE.

Effects of E2 on NO levels and iNOS activity in placental homogenate. ELISAs were performed to detect NO levels and iNOS activity in the placental homogenate using NO and iNOS kits for rats. NO and iNOS levels were increased in the L-NAME group compared with those in the control group ( $\mathrm{P}<0.001$; Fig. 2B and $\mathrm{C})$. However, the NO and iNOS activity did not significantly differ between the L-NAME and L-NAME+NS groups. E2 administration partially inhibited the L-NAME-induced elevation of placental NO and iNOS activity $(\mathrm{P}<0.001$; Fig. 2B and $\mathrm{C})$.

Effects of E2 on inflammatory cytokines in serum and placental homogenate. The levels of serum IL-1ß (Fig. 3A), IL-6 (Fig. 3B), IFN- $\gamma$ (Fig. 3C), MCP-1 (Fig. 3D) and sFlt-1 (Fig. 3E) in the L-NAME group were significantly higher compared with those in the control group. Following treatment with E2, the L-NAME + E2 group exhibited a decrease in these inflammatory cytokines in the serum compared with those in the L-NAME and L-NAME + NS groups. In addition, the protein expression of inflammatory cytokines in the placenta homogenate was detected using western blot analysis (Fig. 3F). The trends of the placental protein expression of these inflammatory cytokines in the different groups were consistent with the serum levels. The correlation between sFlt-1 and IL-1 $\beta$, IL-6, IFN- $\gamma$ and MCP-1 expression in serum was assessed using Pearson's correlation analysis and the results revealed that sFlt-1 had a tendency towards a weak positive correlation with IL-1 $\beta$ (Fig. 3G, $\mathrm{R}^{2}=0.3647, \mathrm{P}=0.0376$ ), IL-6 (Fig. $3 \mathrm{H}, \mathrm{R}^{2}=0.3372, \mathrm{P}=0.0477$ ), IFN- $\gamma$ (Fig. 3I, $\mathrm{R}^{2}=0.3863$, $\mathrm{P}=0.0310$ ) and MCP-1 (Fig. $3 \mathrm{~J}, \mathrm{R}^{2}=0.5132, \mathrm{P}=0.0088$ ). These results indicated that in rats with $\mathrm{PE}, \mathrm{E} 2$ administration effectively suppressed the inflammatory response.

Effects of E2 on adhesion factors and angiogenic factors in the placenta. Western blot analysis indicated that treatment with L-NAME increased the expression levels of CD49d, ICAM1 and LFA-1 compared with those in the control group $(\mathrm{P}<0.001$; Fig. $4 \mathrm{~A}$ and $\mathrm{B})$, whereas $\mathrm{E} 2$ treatment decreased their expression levels compared with those in the L-NAME and L-NAME + NS groups $(\mathrm{P}<0.001$; Fig. 4A and B). In addition, the protein levels of MMP2, MMP9 and VCAM1 were elevated in the L-NAME group compared with those in the control group $(\mathrm{P}<0.001$; Fig. $4 \mathrm{C}$ and $\mathrm{D}$ ); however, the expression of these proteins was downregulated in the L-NAME + E2 group compared with that in the L-NAME and L-NAME + NS groups $(\mathrm{P}<0.001$; Fig. $4 \mathrm{C}$ and D). Therefore, E2 treatment reduced endothelial dysfunction in rats with PE.

Effects of E2 on the expression of ERa36 in the placenta. As presented in Fig. 5A, compared with that in the control group, L-NAME treatment significantly decreased the mRNA levels of ER $\alpha 36(\mathrm{P}<0.001)$, which were partially restored by E2 treatment $(\mathrm{P}<0.01)$. The results of the western blot analysis of the protein levels of ER $\alpha 36$ were consistent with the RT-qPCR results (Fig. 5B). The protein levels of ER $\alpha$, ER $\beta$ and GPER were also assessed by western blot analysis; treatment with L-NAME induced a decrease in the protein expression of ER $\alpha$ and ER $\beta$, whereas E2 partially reversed 
A

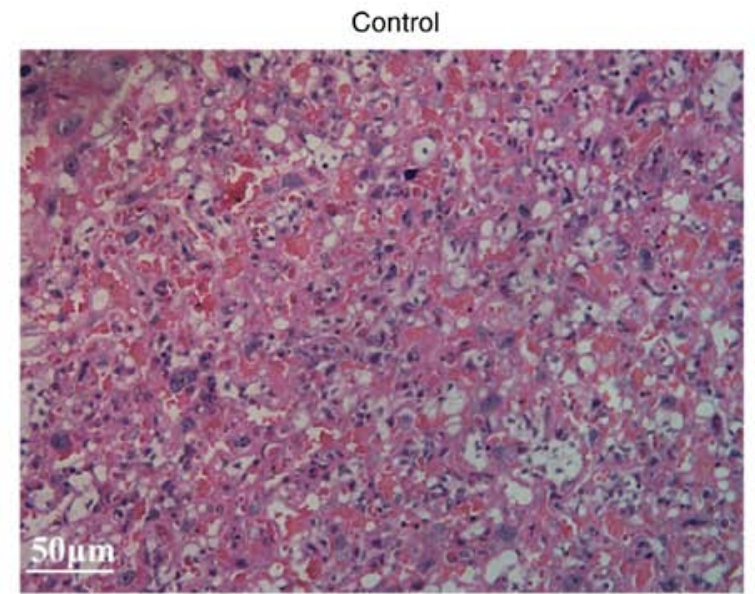

L-NAME+NS
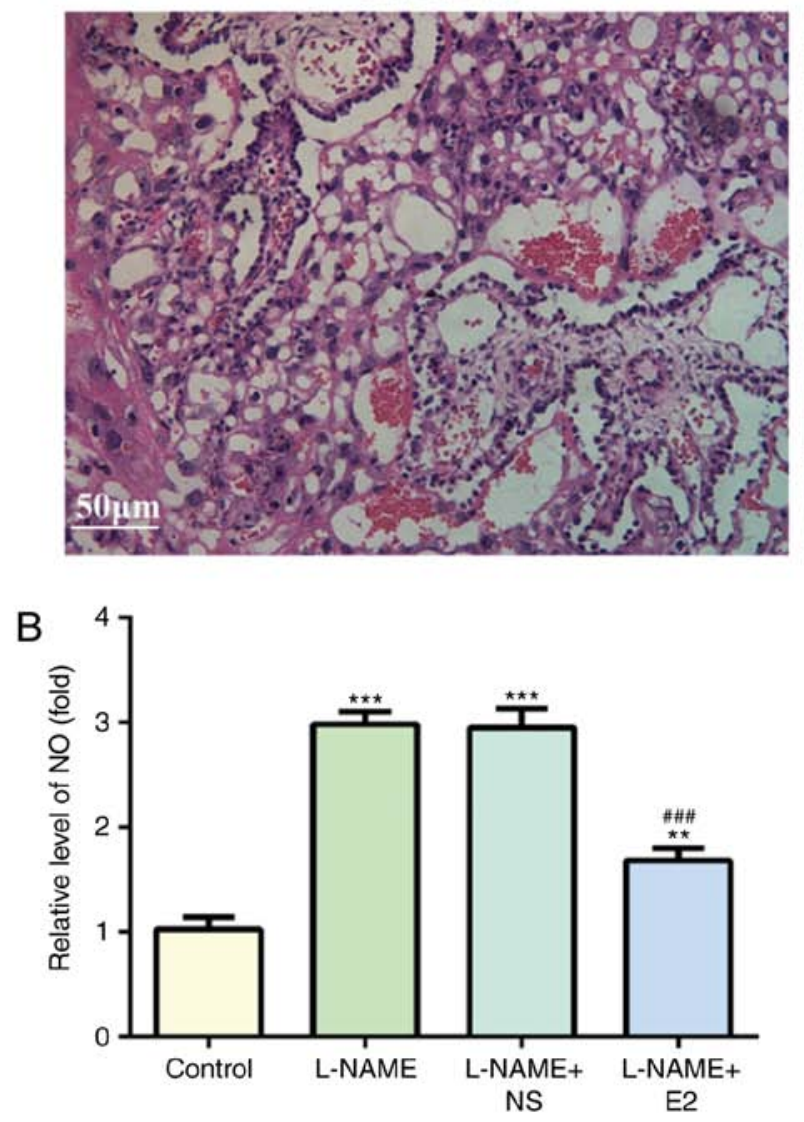

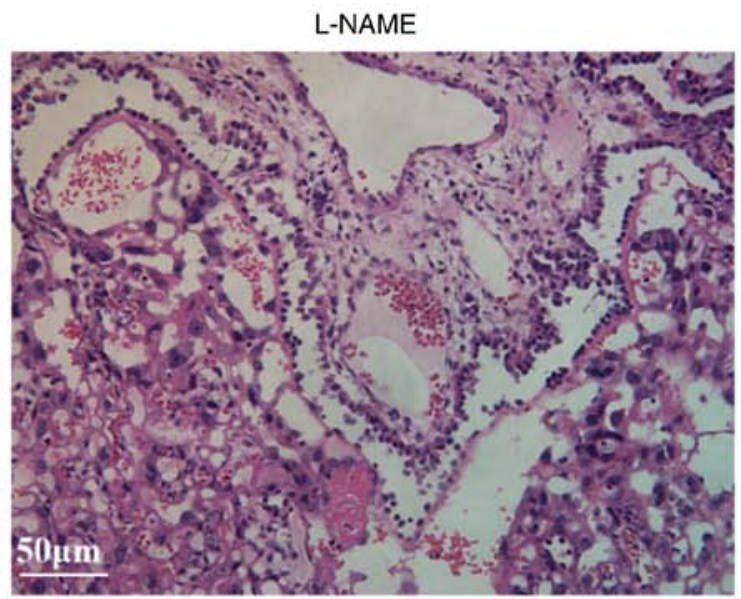

L-NAME+E2
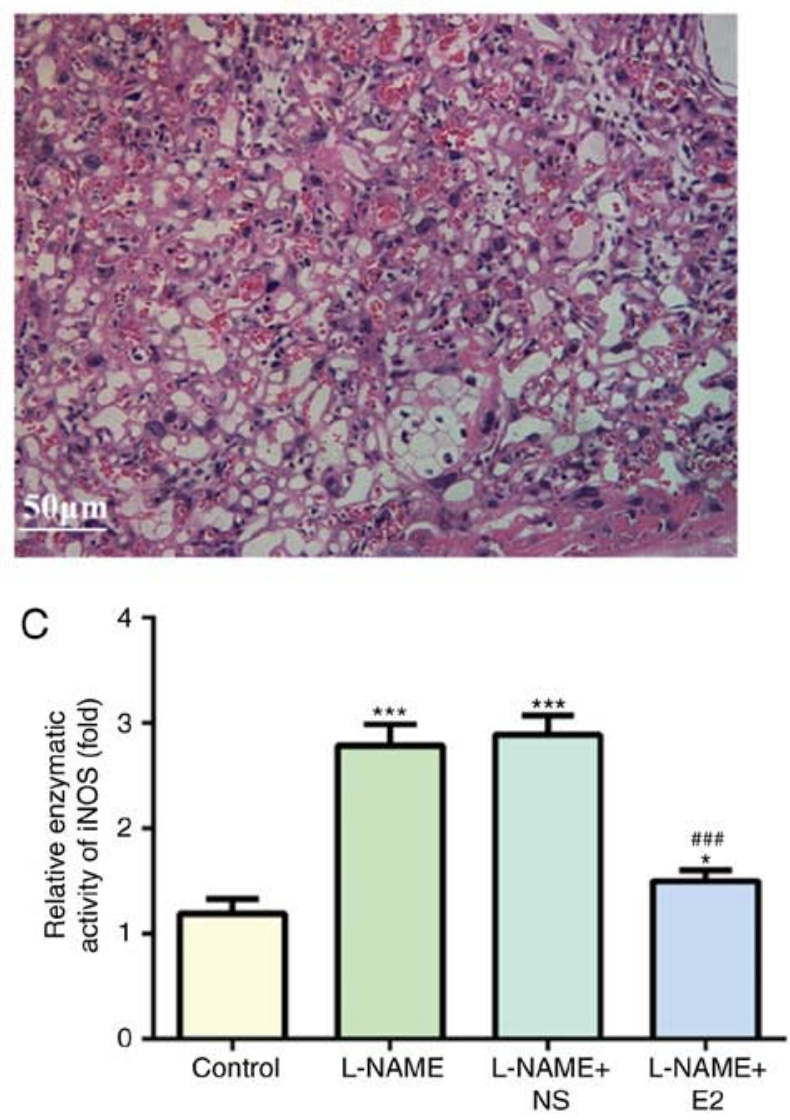

Figure 2. Effects of $\mathrm{E} 2$ on placenta damage, NO level and iNOS activity. (A) Hematoxylin and eosin staining of placenta. Magnification, x200. (B) Relative NO level and (C) iNOS activity in placenta. $\mathrm{n}=12$ rats/group. $\mathrm{P}<0.05,{ }^{* *} \mathrm{P}<0.01$ and ${ }^{* * * *} \mathrm{P}<0.001$ vs. control; ${ }^{* \# \#} \mathrm{P}<0.001$ vs. L-NAME and L-NAME + NS. L-NAME, $\mathrm{N}$ (omega)-nitro-L-arginine methyl ester; NS, normal saline; E2, estradiol; NO, nitric oxide; iNOS, inducible NO synthase.

these effects (Fig. 5C). However, GPER expression was not affected by L-NAME or E2, and no significant differences were observed among the four groups. In addition, the IF assay indicated high expression of ER $\alpha 36$ (green) in the placenta of the control group, whereas L-NAME treatment caused a significant downregulation of ER $\alpha 36$ expression (Fig. 5D). By contrast, ER $\alpha 36$ expression (green) was upregulated in the L-NAME + E2 group compared with that in the L-NAME and L-NAME + NS groups (Fig. 5D). These results indicated that the combination of E2 with ERs (especially ER 236 ) was involved in the regulation of inflammation and endothelial function in rats with PE.
Effects of E2 on the expression of key molecules involved in the TLR4 signaling pathway in the placenta. Western blot analysis indicated that following treatment with L-NAME, the expression levels of TLR4, MyD88, p-IRAK4 and TRAF6 were increased compared with those in the control group $(\mathrm{P}<0.001$; Fig. 6); however, E2 administration significantly reduced the expression levels of these proteins compared with those in the L-NAME and L-NAME + NS groups ( $<<0.001$; Fig. 6). Of note, total (t)-IRAK4 expression was not significantly altered among the four groups. Overall, these results suggested that the TLR4 signaling pathway may serve a functional role in rats with $\mathrm{PE}$. 

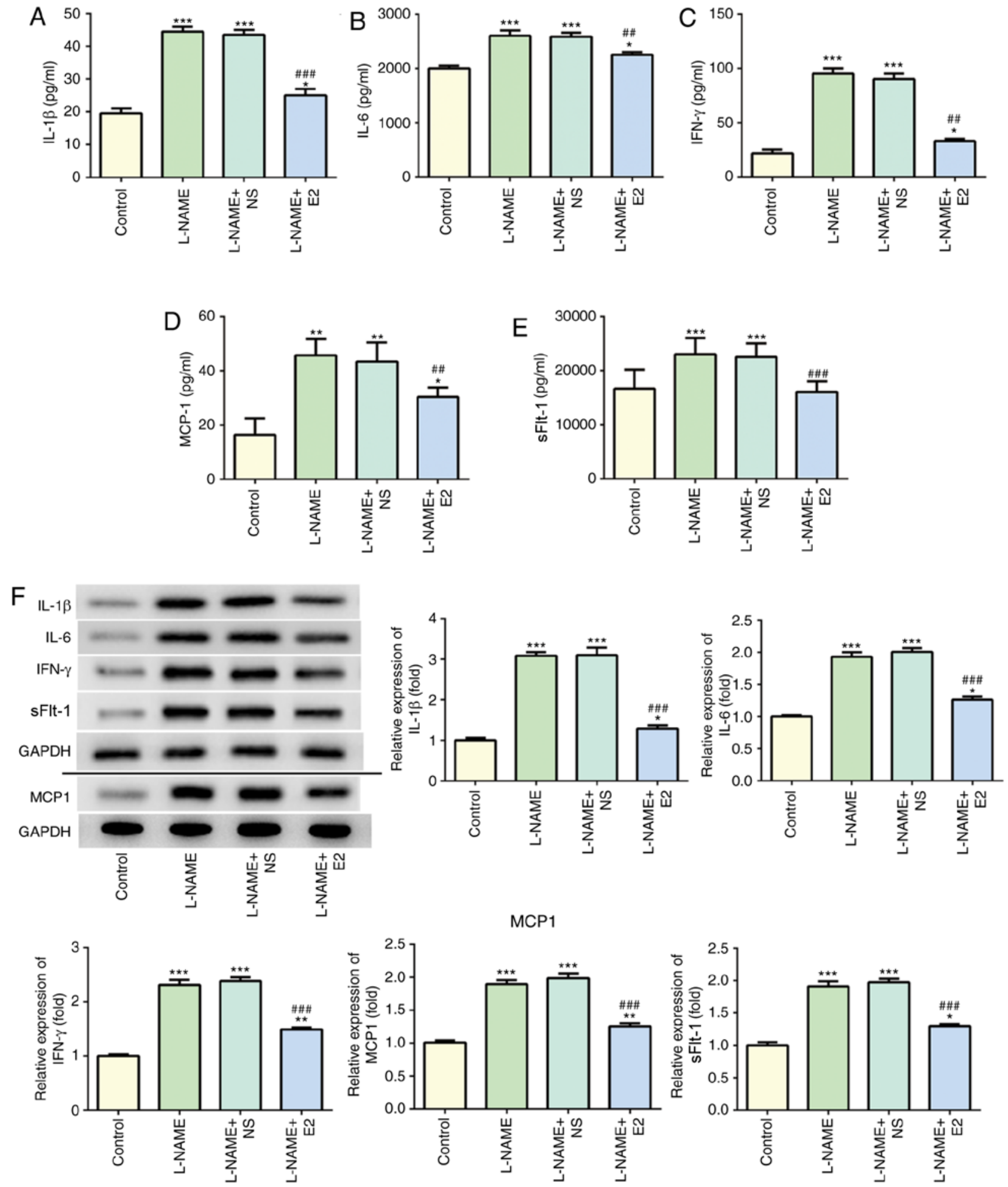

Figure 3. Effects of E2 on the levels of inflammatory cytokines in the serum and placenta of rats with preeclampsia. (A-E) Determination of serum (A) IL-1 $\beta$, (B) IL-6, (C) IFN- $\gamma$, (D) MCP-1 and (E) SFlt-1 levels. (F) Western blot analysis of IL-1 $\beta$, IL-6, IFN- $\gamma$, MCP-1 and SFlt-1 protein expressions among the four groups. Data was presented as mean $\pm \mathrm{SD}$ ( $\mathrm{n}=12$ per group). ${ }^{*} \mathrm{P}<0.05,{ }^{* * *} \mathrm{P}<0.01$ and ${ }^{* * *} \mathrm{P}<0.001$ vs. control; ${ }^{\# \#} \mathrm{P}<0.01$ and ${ }^{\# \# *} \mathrm{P}<0.001$ vs. L-NAME and L-NAME + NS

\section{Discussion}

The novel finding of the present study was that treatment with E2 attenuated the adverse pregnancy outcomes in a rat model of L-NAME-induced PE, and these effects were associated with a decrease in inflammation and endothelial dysfunction, as well as histological improvement in the placenta. In addition, these results were supported by a significant decrease in the rate of stillbirths and the levels of NO and iNOS, accompanied by a reduction of the inflammatory cytokines IL- $1 \beta$, IL-6, IFN- $\gamma$, MCP-1 and sFlt-1. The L-NAME-induced rat model of PE is accepted as a method of inducing experimental hypertension, resulting in a condition similar to clinical PE (19). To the best of our knowledge, the present study was the first to explore 

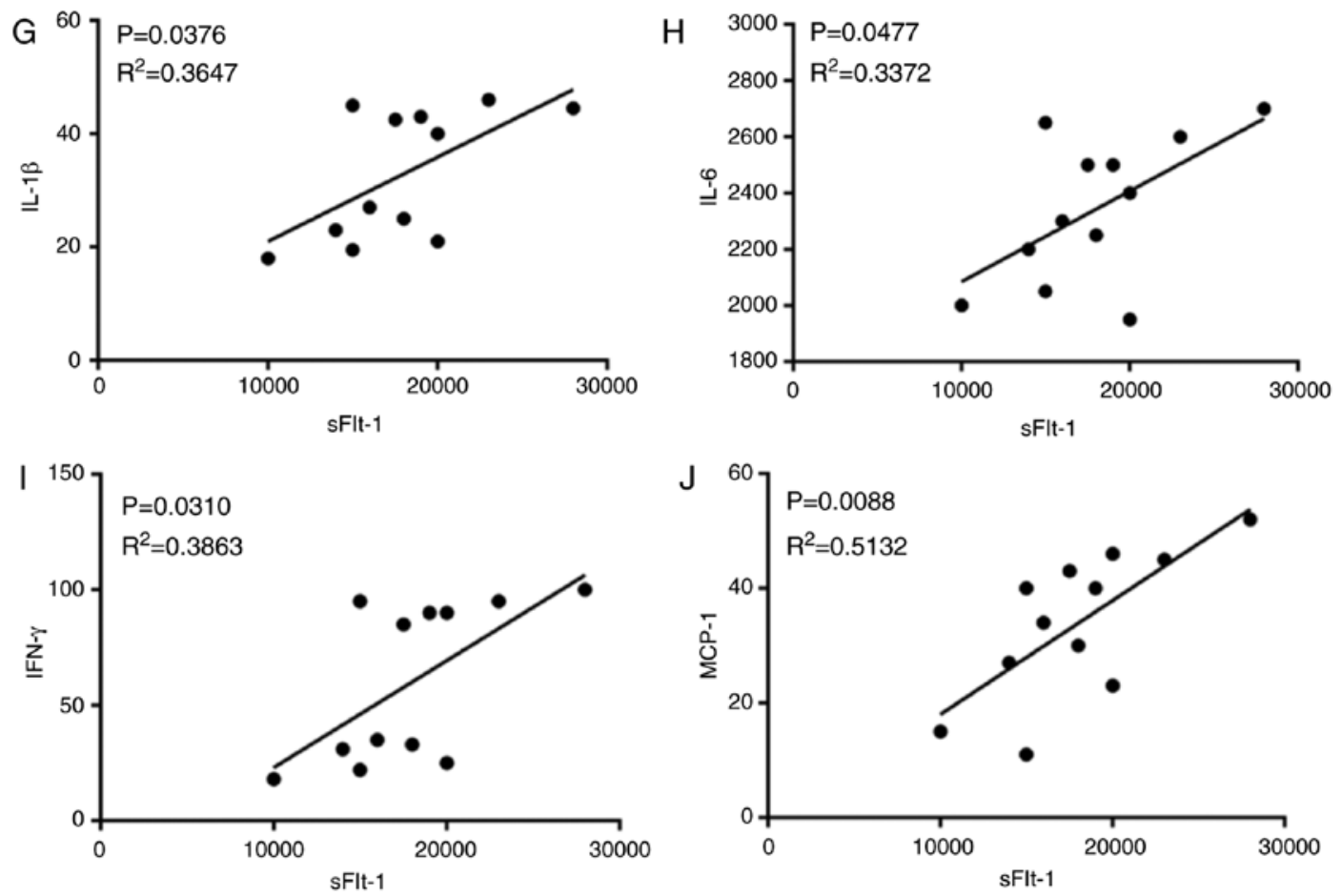

Figure 3. Continued. Effects of E2 on the levels of inflammatory cytokines in the serum and placenta of rats with preeclampsia. (G-J) Pearson's correlation analysis of sFlt-1 expression with (G) IL-1, (H) IL-6, (I) IFN- $\gamma$ and (J) MCP-1 expression in the serum. $\mathrm{n}=12$ rats/group. IL, interleukin; IFN- $\gamma$, interferon- $\gamma$; MCP-1, monocyte chemoattractant protein 1; sFlt-1, soluble Fms-like tyrosine kinase-1; L-NAME, N (omega)-nitro-L-arginine methyl ester; NS, normal saline; E2, estradiol.
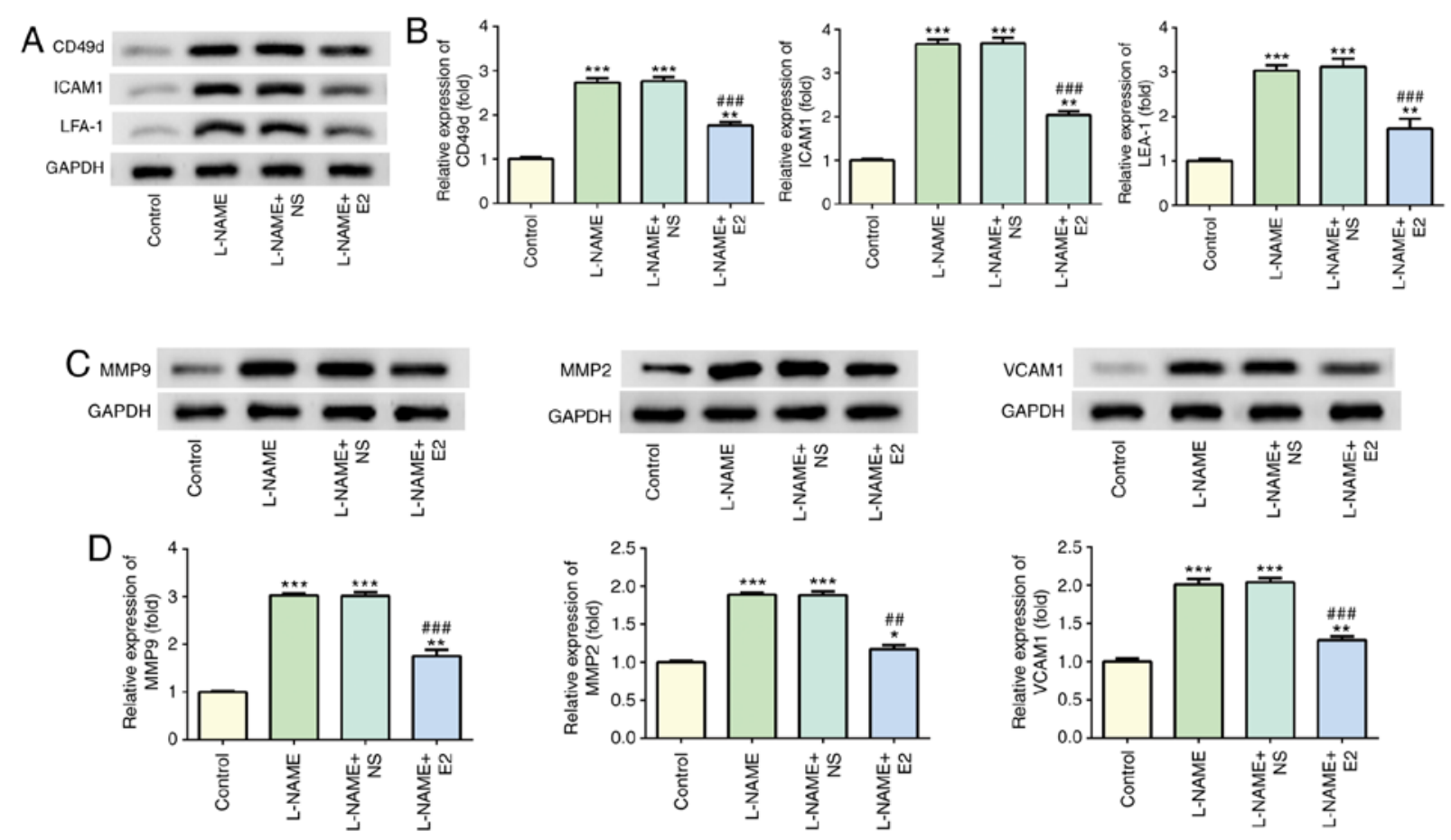

Figure 4. Effects of E2 on the levels of adherence and angiogenic factors. (A) Representative western blot images demonstrating the expression of CD49d, ICAM1 and LFA-1 in the four groups. (B) Relative protein expression levels of CD49d, ICAM1 and LFA-1. (C) Representative western blot images demonstrating the expression of MMP2, MMP9 and VCAM1 in the placenta in the four groups. (D) Relative protein expression of MMP2, MMP9 and VCAM1. $\mathrm{n}=12$ rats/group. ${ }^{*} \mathrm{P}<0.05,{ }^{* *} \mathrm{P}<0.01$ and ${ }^{* * *} \mathrm{P}<0.001$ vs. control; ${ }^{\# \#} \mathrm{P}<0.01$ and ${ }^{\# \# \#} \mathrm{P}<0.001$ vs. L-NAME and L-NAME + NS. E2, estradiol; ICAM1, intercellular adhesion molecule-1; LFA-1, leukocyte function-associated antigen; MMP, matrix metallopeptidase; VCAM1, vascular cell adhesion molecule-1; L-NAME, $\mathrm{N}$ (omega)-nitro-L-arginine methyl ester; NS, normal saline.

the effect of exogenous E2 on rats with PE and the underlying molecular mechanisms of the pathological process.
Previous studies have indicated abnormal changes in serum biochemical indexes and pregnancy outcomes in rats 

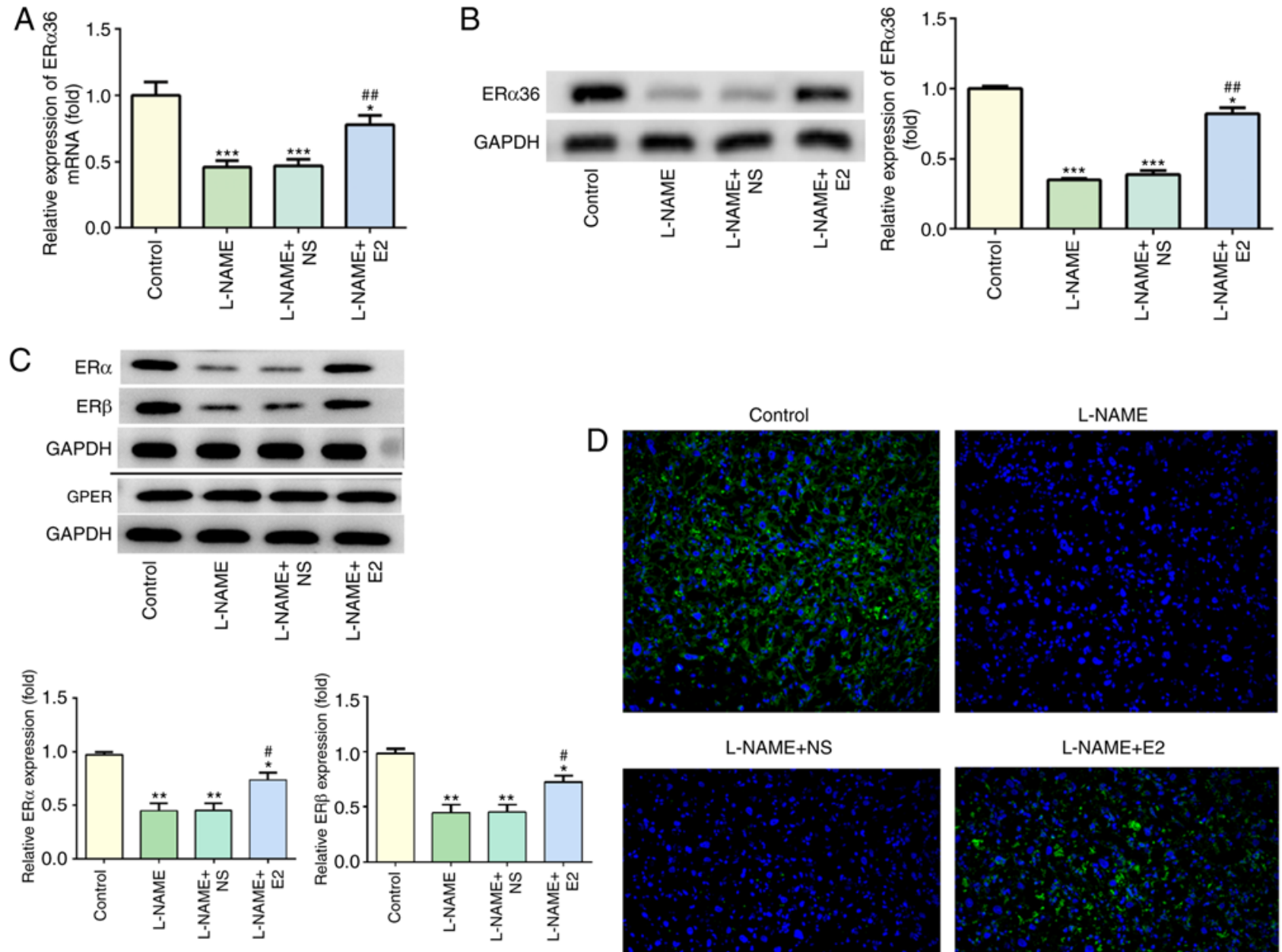
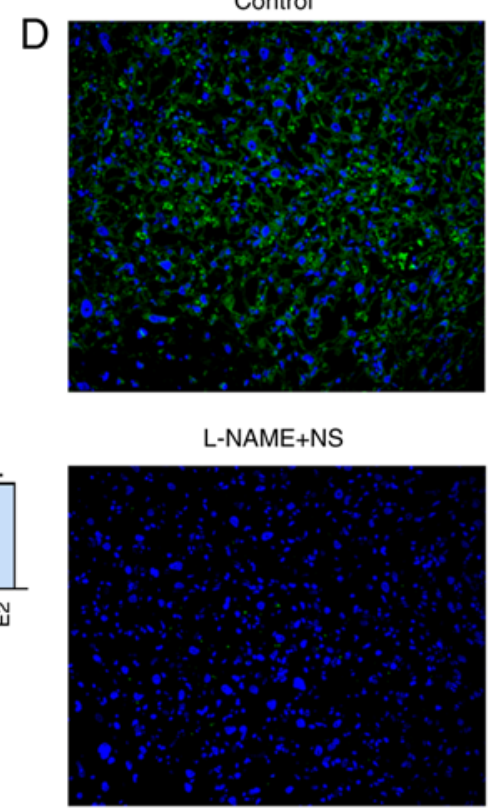
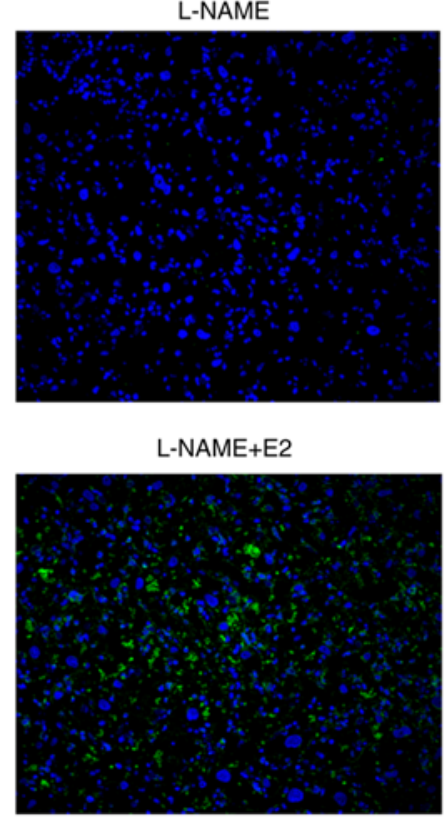

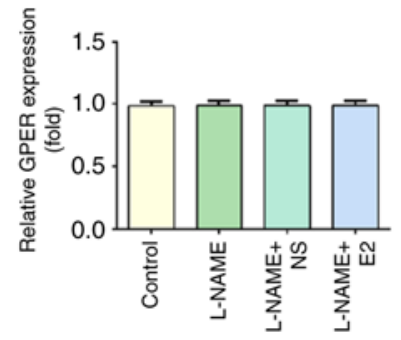

Figure 5. Effects of E2 on the expression of ER $\alpha 36$ in the placenta of rats with preeclampsia. (A) Reverse transcription-quantitative PCR of ER $\alpha 36$ mRNA in the four groups. (B) Western blot detection and statistical analysis for ER $\alpha 36$ expression in the four groups. (C) Representative images and statistical analysis of western blot detection of ER $\alpha, E R \beta$ and GPER expression among the four groups. (D) Immunofluorescence of ER $\alpha 36$ expression (green) with DAPI counterstaining (blue). Magnification, $\mathrm{x} 200 . \mathrm{n}=12$ rats/group. ${ }^{*} \mathrm{P}<0.05,{ }^{* *} \mathrm{P}<0.01$ and ${ }^{* * *} \mathrm{P}<0.001$ vs. control; ${ }^{*} \mathrm{P}<0.05$ and ${ }^{\# \#} \mathrm{P}<0.01$ vs. L-NAME and $\mathrm{L}-\mathrm{NAME}+\mathrm{NS}$. E2, estradiol; ER, estrogen receptor; GPER, G protein-coupled ER; L-NAME, N (omega)-nitro-L-arginine methyl ester; NS, normal saline.

with PE (20,21), which were consistent with the results of the present study. The levels of BP, urine protein and fetal death were increased, whereas fetal body weight was decreased in the L-NAME group in the present study. Hypertension is one of the pathophysiological factors resulting in PE and injuries of the systematic inflammatory response (22). E2 improved the biochemical indexes and neonatal outcome by reducing $\mathrm{BP}$, urine protein and the rate of stillbirths, increasing fetal weight and attenuating pathological injury, which indicated that the improvement of PE was associated with E2 treatment. Previous studies have demonstrated that L-NAME induced an increase in BP in rats and that the lower production of iNOS and NO participated in the adaptive reconstruction of vasculature occurring during normal pregnancy and served an important role in maintaining constant vascular tension and the stability of blood pressure $(23,24)$. Akram et al $(25)$ have reported that estrogen serves a protective role in PE by affecting the renin-angiotensin-aldosterone system to increase the blood volume and regulating the activity of endothelial NO synthase to induce the release of vasoconstrictors. In the present study, treatment of pregnant rats with L-NAME elevated the production of NO and iNOS to cause oxidative stress and impair endothelial function in early hypertension. The results of the present study also suggested that E2 may be a beneficial treatment for the symptoms of PE in agreement with a previous study (25).

The high levels of IL-1 $\beta$, IL- 6 , IFN- $\gamma$ and MCP-1 in the serum and placenta tissue of rats with PE may be linked to the inflammatory response, suggesting that inflammatory cytokines may participate in the adverse events in PE (26). In 

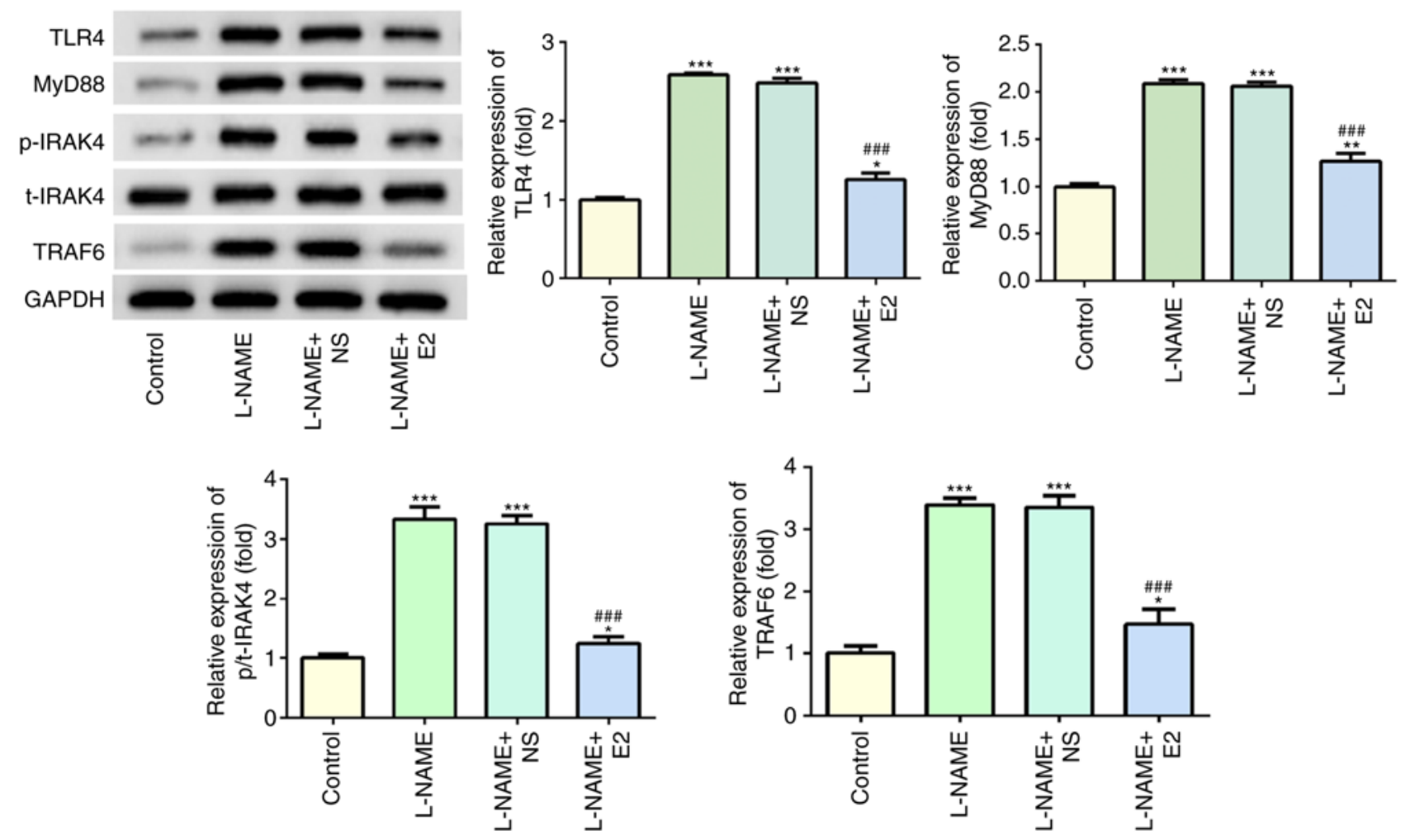

Figure 6. Effects of E2 on the activation of the TLR4 signaling pathway. The expression and statistical analysis of TLR4, MyD88, p-IRAK4, t-IRAK4 and TRAF6 by western blotting. $\mathrm{n}=12$ rats/group. ${ }^{*} \mathrm{P}<0.05,{ }^{* *} \mathrm{P}<0.01$ and ${ }^{* * *} \mathrm{P}<0.001$ vs. control; ${ }^{\# \# "} \mathrm{P}<0.001$ vs. L-NAME and L-NAME + NS. E2, estradiol; L-NAME, N (omega)-nitro-L-arginine methyl ester; NS, normal saline; TLR4, toll-like receptor 4; MyD88, myeloid differentiation primary response 88; IRAK4, interleukin-1 receptor-associated kinase 4; p, phospho; t, total; TRAF6, TNF receptor-associated factor 6.

the present study, treatment with $\mathrm{E} 2$ resulted in a reduction in the levels of IL-1 $\beta$, IL-6, IFN- $\gamma$ and MCP-1 in the serum and placenta of rats with PE, indicating the anti-inflammatory effect of exogenous estrogen. The major alterations associated with PE are likely to trigger local oxidative stress, and re-oxygenation may expand the local effects, including the formation of reactive oxygen species, activation of the maternal inflammatory system and acceleration of apoptosis that may limit the establishment of normal placentation and cause imbalance between pro-angiogenic factors, including sFLT-1 and VCAM-1 (3). In addition, PE may be associated with increased production of MCP-1 and IL-8, which are regulated by signaling mechanisms sensitive to oxidative stress (27). Inflammation is closely associated with angiogenesis. Therefore, the correlation among these factors was analyzed in the present study, and a weak positive correlation between sFLT-1, inflammatory cytokines and MCP-1 was revealed, indicating that sFlt-1 and MCP-1 may lead to the general activation of the maternal inflammatory system, endothelial dysfunction and the limitation of placental vascularization. In addition, E2 may decrease the levels of sFlt1 and MCP-1 to reverse endothelial dysfunction and restricted placental angiogenesis, which may achieve effective treatment of PE.

High expression of ICAM-1 has been previously detected in epithelial cells and the stroma of abortion-prone fetuses in maternal rats, which causes increased recruitment of lymphocytes expressing LFA-1 from the blood into the uterus (28). The levels of IL- $1 \beta$, TNF- $\alpha$ and IFN- $\gamma$ are increased in lymphocytes, and stress further increases the expression of ICAM-1 in the endothelium (29). Inhibition of ICAM-1/LFA-1-mediated intercellular adhesion events may restore the fetal immune acceptance in challenged pregnancies (28). Studies have reported that ICAM-1 and VCAM-1 are increased in the serum or plasma of patients with PE (30). CD49d, an inflammation-associated adhesion molecule expressed on neutrophils and monocytes, binds to VCAM-1 (31). The present result exhibited that L-NAME induced an increase of CD49d, ICAM-1, LFA-1 and VCAM-1 expression levels, which were significantly reversed by E2 administration. This indicated that E2 may alleviate endothelial dysfunction in PE rats by reducing the adhesion of placental tissue and the process of angiogenesis.

ER $\alpha 36$, which is a membrane variant of ER $\alpha$, is also affected by the dysregulation of estrogen signaling (32). ER $\alpha$ has been demonstrated to suppress the activity of ER $\alpha 36$ promoter in an estrogen-independent manner (33). ER $\alpha 36$ has been identified as a mediator of E2 action in the malignant liver and may be involved in the occurrence and development of various tumors $(34,35)$. Consistent with the previous results, the results of the present study indicated that the induction of E2 after L-NAME treatment suppressed the expression of ER $\alpha 36, \mathrm{ER} \alpha$ and ER $\beta$ in the placenta of rats with PE compared with that in normal pregnant rats. E2 administration induced upregulation of ER $\alpha 36, E R \alpha$ and $E R \beta$ expression compared with that in the L-NAME group. Among the ERs, the changes in ER $\alpha 36$ levels were the most significant. The expression changes of other estrogen receptors may eventually lead to changes in ER $\alpha 36$ expression, which was why 
ER $\alpha 36$ was selected as the main research object of the present study. A previous study reported that E2 suppressed the binding activity of NF- $\mathrm{KB}$ mediated by ER $\alpha 66$ and reduced the expression of MMP2, MMP9, cyclin A and cyclin D1, resulting in cell cycle arrest and promoting cell apoptosis (36). Apoptotic processes and endothelial dysfunction are common in PE (3). The results of the present study indicated that that E2 suppressed the expression of MMP9, MMP2 and VCAM-1 in placental tissue induced by L-NAME treatment. ER $\alpha 36$ has been demonstrated to be located in the cytoplasm as well as on the cell surface, where it mediates non-genomic estrogen signaling through cross-talk with growth factor receptors and other signaling molecules (including mitogen-activated protein kinase/ERK and PI3K/AKT) to promote cell proliferation, invasion and migration, as well as resistance to endocrine therapy (37). Therefore, it was hypothesized in the present study that E2 may bind to ER $\alpha 36$ to regulate the expression of the above factors through certain signaling pathways, such as the TRL4 signaling pathway.

In the present study, the anti-inflammatory, antioxidant and anti-vascular dysfunction properties of E2 were indicated to be, at least in part, mediated by the suppression of the TLR4 pathway through the inhibition of MyD88 and TRAF6 expression, as well as phosphorylation of IRAK4. A previous study has reported that the TLR4 signaling pathway serves an important role in autoimmune disease (38) and the inflammatory response and pathological damage associated with various diseases in humans $(39,40)$. MyD88 and TRAF-6 are important intracellular adaptor proteins that function as effectors of the TLR4 signaling cascade (41). MyD88 activates and phosphorylates IRAK4, leading to the recruitment of TRAF6 and promoting inflammation (42). The intracellular signaling cascade is activated by TLR4 by recruiting IRAK4 to the membrane (43). The TLR4-dependent signaling pathway has been reported to be detrimental to trophoblast function (44). These previous studies are in accordance with the results of the present study, as the TLR4/MyD88/IRAK4/TRAF6 signaling pathway was activated in rats with PE. The results of the present study suggested that the regulation of the TLR4/MyD88/IRAK4/TRAF6 pathway may be involved in the effects of E2 against L-NAME-induced pathological processes of PE. The binding of E2 to ER 36 may participate in the regulation of angiogenesis and inflammation by mechanisms dependent on TLR4 activation in PE.

In summary, the results of the present study demonstrated that E2 may improve adverse pregnancy outcomes induced by L-NAME in rats. The protective effects of E2 may be partially exerted by binding to ER $\alpha 36$, regulation of inflammatory, adherence and placental angiogenic factors and deactivation of TLR4/MyD88/IRAK4/TRAF6 signaling. Therefore, E2 may be a potential therapeutic for treating PE.

\section{Acknowledgements}

Not applicable.

\section{Funding}

No funding was received.

\section{Availability of data and materials}

The datasets used and analyzed during the current study are available from the corresponding author on reasonable request.

\section{Authors' contributions}

ZHL designed the experiments and wrote the manuscript. ZHL, JJ and XYS performed the experiments and analyzed the data. All authors read and approved the final version of the manuscript.

\section{Ethics approval and consent to participate}

The protocols of the animal experiments followed the NIH Guide for the Care and Use of Laboratory Animals and were approved by the Experimental Animal Ethics Committee of Kunming Medical University (Kunming, China) and the Commission for Animal Experimentation of The People's Hospital of the Xishuangbanna Dai Nationality Autonomous Prefecture.

\section{Patient consent for publication}

Not applicable.

\section{Competing interests}

The authors declare that they have no competing interests.

\section{References}

1. Walker CK, Krakowiak P, Baker A, Hansen RL, Ozonoff S and Hertz-Picciotto I: Preeclampsia, placental insufficiency, and autism spectrum disorder or developmental delay. JAMA Pediatr 169: 154-162, 2015.

2. Hod T, Cerdeira AS and Karumanchi SA: Molecular mechanisms of preeclampsia. Cold Spring Harb Perspect Med 5, 2015.

3. Ramos JGL, Sass N and Costa SHM: Preeclampsia. Rev Bras Ginecol Obstet 39: 496-512, 2017.

4. Borzychowski AM, Croy BA, Chan WL, Redman CW and Sargent IL: Changes in systemic type 1 and type 2 immunity in normal pregnancy and pre-eclampsia may be mediated by natural killer cells. Eur J Immunol 35: 3054-3063, 2005.

5. Biondi C, Pavan B, Lunghi L, Fiorini S and Vesce F: The role and modulation of the oxidative balance in pregnancy. Curr Pharm Des 11: 2075-2089, 2005.

6. Kiprono LV, Wallace K, Moseley J, Martin J Jr and Lamarca B: Progesterone blunts vascular endothelial cell secretion of endothelin-1 in response to placental ischemia. Am J Obstet Gynecol 209: 44.e1-e6, 2013.

7. Wei J, Satomi M, Negishi Y, Matsumura Y, Miura A, Nishi Y, Asakura $\mathrm{H}$ and Takeshita T: Effect of sera on the adhesion of natural killer cells to the endothelium in severe pre-eclampsia. J Obstet Gynaecol Res 32: 443-448, 2006.

8. Mihu D, Razvan C, Malutan A and Mihaela C: Evaluation of maternal systemic inflammatory response in preeclampsia. Taiwan J Obstet Gynecol 54: 160-166, 2015.

9. de Oliveira LG, Karumanchi A and Sass N: Preeclampsia: Oxidative stress, inflammation and endothelial dysfunction. Rev Bras Ginecol Obstet 32: 609-616, 2010 (In Portuguese).

10. Tranquilli AL, Dekker G, Magee L, Roberts J, Sibai BM, Steyn W, Zeeman GG and Brown MA: The classification, diagnosis and management of the hypertensive disorders of pregnancy: A revised statement from the ISSHP. Pregnancy Hypertens 4: 97-104, 2014.

11. Wei J, Chen Q, James JL, Stone PR and Chamley LW: IL-1 beta but not the NALP3 inflammasome is an important determinant of endothelial cell responses to necrotic/dangerous trophoblastic debris. Placenta 36: 1385-1392, 2015. 
12. Southcombe JH, Redman CW, Sargent IL and Granne I: Interleukin-1 family cytokines and their regulatory proteins in normal pregnancy and pre-eclampsia. Clin Exp Immunol 181: 480-490, 2015

13. Khalil RA: Sex hormones as potential modulators of vascular function in hypertension. Hypertension 46: 249-254, 2005.

14. Duckles SP and Miller VM: Hormonal modulation of endothelial NO production. Pflugers Arch 459: 841-851, 2010.

15. Salas SP, Marshall G, Gutiérrez BL and Rosso P: Time course of maternal plasma volume and hormonal changes in women with preeclampsia or fetal growth restriction. Hypertension 47: 203-208, 2006

16. Zheng JJ, Wang HO, Huang $M$ and Zheng FY: Assessment of ADMA, estradiol, and progesterone in severe preeclampsia. Clin Exp Hypertens 38: 347-351, 2016.

17. Cikos S, Bukovská A and Koppel J: Relative quantification of mRNA: Comparison of methods currently used for real-time PCR data analysis. BMC Mol Biol 8: 113, 2007.

18. Feng J, Wang X, Li H, Wang L and Tang Z: Silencing of Annexin A1 suppressed the apoptosis and inflammatory response of preeclampsia rat trophoblasts. Int J Mol Med 42: 3125-3134, 2018.

19. Kanashiro CA, Cockrell KL, Alexander BT, Granger JP and Khalil RA: Pregnancy-associated reduction in vascular protein kinase $\mathrm{C}$ activity rebounds during inhibition of NO synthesis. Am J Physiol Regul Integr Comp Physiol 278: R295-R303, 2000.

20. Souza CO, Peracoli MT, Weel IC, Bannwart CF, Romão M, Nakaira-Takahagi E, Medeiros LT, Silva MG and Peraçoli JC: Hepatoprotective and anti-inflammatory effects of silibinin on experimental preeclampsia induced by L-NAME in rats. Life Sci 91: 159-165, 2012

21. Doering TP, Haller NA, Montgomery MA, Freeman EJ and Hopkins MP: The role of AT1 angiotensin receptor activation in the pathogenesis of preeclampsia. Am J Obstet Gynecol 178: 1307-1312, 1998

22. Beckers KF and Sones JL: Maternal microbiome and the hypertensive disorder of pregnancy, preeclampsia. Am J Physiol Heart Circ Physiol, 2019

23. de Moura RS, Resende AC, Moura AS and Maradei MF: Protective action of a hydroalcoholic extract of a vinifera grape skin on experimental preeclampsia in rats. Hypertens Pregnancy 26: 89-100, 2007.

24. Conrad KP, Joffe GM, Kruszyna H, Kruszyna R, Rochelle LG, Smith RP, Chavez JE and Mosher MD: Identification of increased nitric oxide biosynthesis during pregnancy in rats. FASEB J 7: 566-571, 1993

25. Akram SK, Sahlin L, Ostlund E, Hagenäs L, Fried G and Söder O: Placental IGF-I, estrogen receptor, and progesterone receptor expression, and maternal anthropometry in growth-restricted pregnancies in the Swedish population. Horm Res Paediatr 75: 131-137, 2011.

26. Fodor P, White B and Khan R: Inflammation-The role of ATP in pre-eclampsia. Microcirculation, 2019.

27. Kauma S, Takacs P, Scordalakes C, Walsh S, Green K and Peng T: Increased endothelial monocyte chemoattractant protein-1 and interleukin-8 in preeclampsia. Obstet Gynecol 100: 706-714, 2002.

28. Blois S, Tometten M, Kandil J, Hagen E, Klapp BF, Margni RA and Arck PC: Intercellular adhesion molecule-1/LFA-1 cross talk is a proximate mediator capable of disrupting immune integration and tolerance mechanism at the feto-maternal interface in murine pregnancies. J Immunol 174: 1820-1829, 2005.

29. Springer TA: Traffic signals for lymphocyte recirculation and leukocyte emigration: The multistep paradigm. Cell 76: 301-314, 1994.

30. Chaiworapongsa T, Romero R, Yoshimatsu J, Espinoza J, Kim YM, Park K, Kalache K, Edwin S, Bujold E and Gomez R: Soluble adhesion molecule profile in normal pregnancy and pre-eclampsia. J Matern Fetal Neonatal Med 12: 19-27, 2002.
31. Oggé G, Romero R, Chaiworapongsa T, Gervasi MT, Pacora P, Erez O, Kusanovic JP, Vaisbuch E, Mazaki-Tovi S, Gotsch F, et al: Leukocytes of pregnant women with small-for-gestational age neonates have a different phenotypic and metabolic activity from those of women with preeclampsia. J Matern Fetal Neonatal Med 23: 476-487, 2010

32. Xu Z, Liu J, Jianxin C, Yongliang Z and Pan X: 17 $\beta$-Estradiol inhibits testosterone-induced cell proliferation in HepG2 by modulating the relative ratios of 3 estrogen receptor isoforms to the androgen receptor. J Cell Biochem 119: 8659-8671, 2018.

33. Zou Y, Ding L, Coleman M and Wang Z: Estrogen receptor-alpha (ER-alpha) suppresses expression of its variant ER-alpha 36. FEBS Lett 583: 1368-1374, 2009.

34. Cocciadiferro L, Miceli V, Granata OM and Carruba G: Abstract 1852: Merlin/NF2 is associated with elevated aromatase expression and estrogen formation in human liver tissues and liver cancer cells: An unifying model for hepatocellular carcinoma development and progression. Cancer Res 1852, 2015.

35. Liu J, Xu Z, Ma X, Huang B and Pan X: Role of ER- $\alpha 36$ in breast cancer by typical xenoestrogens. Tumour Biol 36: 7355-7364, 2015

36. Xu H, Wei Y, Zhang Y, Xu Y, Li F, Liu J, Zhang W, Han X, Tan R and Shen P: Oestrogen attenuates tumour progression in hepatocellular carcinoma. J Pathol 228: 216-229, 2012.

37. Wang Z, Zhang X, Shen P, Loggie BW, Chang Y and Deuel TF: Identification, cloning, and expression of human estrogen receptor-alpha36, a novel variant of human estrogen receptor-alpha66. Biochem Biophys Res Commun 336: $1023-1027,2005$

38. Rao $\mathrm{Y}$ and $\mathrm{Su}$ J: Insights into the antiviral immunity against grass carp (Ctenopharyngodon idella) reovirus (GCRV) in grass carp. J Immunol Res 2015: 670437, 2015.

39. Meng M, Wang H, Li Z, Guo M and Hou L: Protective effects of polysaccharides from Cordyceps gunnii mycelia against cyclophosphamide-induced immunosuppression to TLR4/TRAF6/NF- $\kappa$ B signalling in $\mathrm{BALB} / \mathrm{c}$ mice. Food Funct 10: 3262-3271, 2019.

40. Wang X, Han C, Qin J, Wei Y, Qian X, Bao Y and Shi W: Pretreatment with salvia miltiorrhiza polysaccharides protects from lipopolysaccharides/d-galactosamine-induced liver injury in mice through inhibiting TLR4/MyD88 signaling pathway. J Interferon Cytokine Res 39: 495-505, 2019.

41. Verstak B, Nagpal K, Bottomley SP, Golenbock DT, Hertzog PJ and Mansell A: MyD88 adapter-like (Mal)/TIRAP interaction with TRAF6 is critical for TLR2- and TLR4-mediated NF-kappaB proinflammatory responses. J Biol Chem 284: 24192-24203, 2009.

42. Shi S, Liang D, Chen Y, Xie Y, Wang Y, Wang L, Wang Z and Qiao Z: Gx-50 reduces $\beta$-amyloid-induced TNF- $\alpha$, IL-1 $\beta$, NO, and PGE2 expression and inhibits NF- $\mathrm{BB}$ signaling in a mouse model of Alzheimer's disease. Eur J Immunol 46: 665-676, 2016.

43. Song J, Han X, Yao YL, Li YM, Zhang J, Shao DY, Hou LS, Fan Y, Song SZ, Lian LH, et al: Acanthoic acid suppresses lipin1/2 via TLR4 and IRAK4 signalling pathways in EtOHand lipopolysaccharide-induced hepatic lipogenesis. J Pharm Pharmacol 70: 393-403, 2018.

44. Leon-Martinez D, Mulla MJ, Han CS, Chamley LW and Abrahams VM: Modulation of trophoblast function by concurrent hyperglycemia and antiphospholipid antibodies is in part TLR4-dependent. Am J Reprod Immunol 80: e13045, 2018

This work is licensed under a Creative Commons Attribution-NonCommercial-NoDerivatives 4.0 International (CC BY-NC-ND 4.0) License. 